\title{
Dietary supplement use among cancer survivors of the NutriNet-Santé cohort study
}

\author{
Camille Pouchieu $^{1 *}$, Philippine Fassier ${ }^{1}$, Nathalie Druesne-Pecollo ${ }^{1}$, Laurent Zelek ${ }^{1}$, Patrick Bachmann ${ }^{2}$, \\ Marina Touillaud ${ }^{2}$, Isabelle Bairati ${ }^{1,3}$, Serge Hercberg ${ }^{1,4}$, Pilar Galan ${ }^{1}$, Patrice Cohen ${ }^{5}$, \\ Paule Latino-Martel ${ }^{1}$ and Mathilde Touvier $^{1}$ \\ ${ }^{1}$ Sorbonne Paris Cité, Epidemiology and Biostatistics Research Centre, Nutritional Epidemiology Research Team (EREN), \\ Inserm U1153, Inra U1125, Cnam, Paris 13, 7 and 5 Universities, Bobigny, France \\ ${ }^{2}$ Cancer, Environment and Nutrition Unit, Anticancer Centre Léon-Bérard, Lyon, France \\ ${ }^{3}$ Laval University Cancer Research Centre, Québec City, QC, Canada \\ ${ }^{4}$ Public Health Department, Avicenne Hospital, Bobigny, France \\ ${ }^{5}$ DySoLa, EA 4701, Rouen University, Rouen, France \\ (Submitted 11 September 2014 - Final revision received 4 December 2014 - Accepted 6 January 2015 - First published online 31 March 2015)
}

\begin{abstract}
Dietary supplements (DS) may influence cancer prognosis. Their use in cancer patients has been described in the United States, but data are largely lacking in Europe and notably in France. The present study's objectives were (1) to assess DS use and its sociodemographic, lifestyle, and dietary correlates in a large sample of French cancer survivors; (2) to evaluate the involvement of physicians in such DS use; and (3) to assess the extent of potentially harmful practices. Data were collected by self-administered web-based questionnaires among participants of the NutriNet-Santé cohort. Data on DS use was available for 1081 cancer survivors. DS users were compared to nonusers with unconditional logistic regressions. DS use was reported by $62 \%$ of women and $29 \%$ of men. Vitamins $\mathrm{D}, \mathrm{B}_{6}, \mathrm{C}$ and $\mathrm{Mg}$ were the most frequently consumed nutrients. $14 \%$ of cancer survivors initiated DS use after diagnosis. For $35 \%$ of the DS consumed, subjects did not inform their attending physician. DS use was associated with a healthier lifestyle (normal weight, never smoking and better diet) and substantially contributed to nutrient intake. $18 \%$ of DS users had potentially harmful DS use practices, such as the simultaneous use of vitamin $\mathrm{E}$ and anticoagulant/antiplatelet agents, the use of $\beta$-carotene and smoking or the use of phyto-oestrogens in hormonedependent cancer patients. The present study suggests that DS use is widespread among cancer survivors, a large amount of that use is performed without any medical supervision and a substantial proportion of that use involves potentially harmful practices. Physicians should be encouraged to more routinely discuss DS use with their cancer patients.
\end{abstract}

Key words: Dietary supplements: Motivations: Correlates: Cancer survivors

When disconcerted by their illness and disappointed by traditional medicine, cancer patients can move towards complementary and alternative medicines, including the use of dietary supplements (DS). However, the impact of DS on cancer prognosis, risk of recurrence and risk of second cancer remains unclear ${ }^{(1)}$. Although the beneficial effects of DS taken during or after cancer treatment are not excluded $^{(2-4)}$, several studies have reported adverse effects of some DS on cancer prognoses ${ }^{(1,5-8)}$. Presently, it is recommended that phyto-oestrogen DS should be avoided with hormone-dependent cancer patients ${ }^{(6,9)}$. Similarly, $\beta$-carotene DS should not be used with cancer patients or with healthy people who are smokers ${ }^{(10-12)}$. In addition, studies have shown that some vitamin/mineral or herbal DS may interact with anti-cancer or other active treatments ${ }^{(9,13-15)}$. This may be particularly problematic if attending physicians have no knowledge of the self-medication practices in their patients. According to a recent review of US studies, 56-68\% of physicians are not aware of DS use among their cancer patients ${ }^{(16)}$.

In this context, it is essential to assess DS use and its correlates in cancer patients and survivors. Such observational studies have been published in the United States ${ }^{(8,16-21)}$. A recent review showed that DS use was widespread in American cancer patients, with a prevalence of vitamin and mineral DS use that varied between 64 and $81 \%{ }^{(16)}$. Between 14 and $32 \%$ of the survivors began taking their supplements after diagnosis $^{(16)}$. Fewer studies provided information on DS use in cancer patients in European countries ${ }^{(22-28)}$, but those

Abbreviation: DS, dietary supplements.

*Corresponding author: C. Pouchieu, fax +33 14838 89 31, email: c.pouchieu@eren.smbh.univ-paris13.fr 
that did showed a prevalence of DS use that varied from 9 to $48 \%$ across countries.

Several sociodemographic and lifestyle characteristics, such as female sex, higher education level and higher income, have been reported to be associated with the use of DS. However, no epidemiological study has been published for France on this topic. Perceptions and attitudes towards food and nutrition may vary significantly across countries. Thus, specific research is needed, especially in the context of the increasing availability of DS from traditional distribution channels but also from Internet sources.

The objectives of the present study were (1) to assess DS use and its sociodemographic, lifestyle and dietary correlates in a large sample of French cancer survivors involved in the NutriNet-Santé cohort; (2) to evaluate the role and involvement of physicians in DS use by their cancer patients; (3) to assess the extent of potentially harmful practices, such as use of $\beta$-carotene DS in smokers, the use of phyto-oestrogen DS in hormone-dependent cancer patients and contraindicated DS-medication simultaneous use.

\section{Methods}

\section{Subjects}

The NutriNet-Santé study is a population-based prospective observational cohort that is followed via the Internet (http://www.etude-nutrinet-sante.fr). Its main objective is to assess the relationships between nutrition and chronic disease risk as well as the determinants of eating behaviour ${ }^{(29)}$. It was launched in France in May 2009. Using mass-media campaigns, adults aged 18 years or older who had access to the Internet were invited to participate. All subjects signed an electronic informed consent. The NutriNet-Santé study was approved by the Institutional Review Board of the French Institute for Health and Medical Research (no. 0000388FWA00005831) and the Commission Nationale de l'Informatique et des Libertés (no. 908450 and no. 909216).

\section{Data collection}

Participants completed several self-administered webbased questionnaires at baseline and then regularly during the follow-up. All baseline questionnaires were tested and compared against traditional assessment methods (paper questionnaires or interviews by a dietitian) ${ }^{(30-32)}$.

Case ascertainment. Participants self-declared any cancer diagnoses during the study follow-up through regular questionnaires and a permanent web-interface. Medical data were then gathered from participants, physicians, and/or hospitals and reviewed by an independent physician expert committee. Pathological reports were used to validate cancer cases and to extract cancer clinical data. Cases were classified using the International Chronic Diseases Classification, 10th Revision, Clinical Modification (ICD-10) ${ }^{(33)}$.

Dietary supplement and medication use. The questionnaire that assessed DS and medication use, which was specifically designed for cancer survivors, was sent in January
2014 to all first-incident primary cancer cases (who were diagnosed after their enrolment in the cohort). In the present study, we considered as DS both regular DS and medicinal supplements that are mainly composed of vitamins and minerals, which are treated as pharmaceutical products in France. In contrast, clinical oral nutritional supplements, such as Renutryl $^{\circledR}$ or Clinutren ${ }^{\circledR}$, were not considered as DS in the survey. Indeed, these specific products, which are rich in energy and/or protein, are administered to undernourished patients to stimulate weight gain and avoid malnutrition.

Participants were asked about their DS use at the time that they completed of the questionnaire ('current use'). In addition, cancer patients were asked to report their DS use since the date of their cancer diagnosis. For each DS, they reported the commercial name, brand, form, number of days of use per year, and number of units per day of use. The questionnaire included an assessment of the circumstances and motivations for DS use (close-ended questions) as well as questions about DS use changes after cancer diagnosis. For each DS, participants were asked if they had told at least one of their attending physicians about their DS use and, when appropriate, the reasons why they did not. Subjects also reported all anti-cancer or other medications (chosen among an exhaustive list based on the VIDAL, a French drug reference database ${ }^{(34)}$ ) that they were taking at the time of the DS questionnaire. A DS composition database was created and implemented based on information found on official brands' websites or direct contact with manufacturers.

Sociodemographic, lifestyle and anthropometric data. Self-administered questionnaires were annually administered during follow-up to collect and update data on sociodemographic, lifestyle and behavioural characteristics, including sex, age, geographical region, marital status, number of children, educational level, smoking status, anthropometry and leisure-time physical activity (which was estimated with the validated international physical activity questionnaire ${ }^{(35)}$ ). Data collected after cancer diagnosis and closest to the DS questionnaire administration were used in the present study.

Dietary data. Each year, participants were asked to complete three non-consecutive self-administered web-based $24 \mathrm{~h}$ dietary records, the days for which are randomly assigned during a 2 -week period ( $2 \mathrm{~d}$ during the week and $1 \mathrm{~d}$ during the weekend). All foods and beverages consumed at breakfast, lunch, dinner and at all other occasions were recorded. For foods with potentially high nutrient variability, participants were also asked to provide the brand name. Participants were asked to estimate the portion size for each reported food and beverage item using a validated photograph booklet ${ }^{(36)}$. These photographs represented more than 250 foods (corresponding to about 1000 generic food items) in three different portion sizes. Along with the two intermediate and two extreme quantities, participants had seven choices of amounts. Daily dietary intakes of energy and nutrients were then calculated using the NutriNet-Santé food composition table ${ }^{(37)}$, which includes more than 2500 different foods. Dietary records from the year closest to the DS questionnaire administration (i.e. 2013 or 2014) were used in dietary data analyses. 


\section{Statistical analyses}

Proportions of DS users (i.e. at least one DS taken after cancer diagnosis) and type of and motivation for DS use were calculated overall and also by sex and main cancer sites (breast and prostate) in a cross-sectional design. For each DS reported in the study, circumstances of DS purchase, duration of use and communication with a physician about this use were described.
DS users and non-users were compared by age and sexadjusted unconditional logistic regression analyses regarding their sociodemographic, anthropometric and lifestyle characteristics (sex, age, geographical region, marital status, number of children, educational level, smoking status, BMI and leisuretime physical activity). OR and their 95\% CI were calculated.

Participants who provided at least two dietary records after cancer diagnosis (328 subjects excluded) and those who were

Table 1. Dietary supplement (DS) use in cancer survivors ( $n$ 1081, NutriNet-Santé cohort study, France, 2014)

(Number of subjects and percentages)

\begin{tabular}{|c|c|c|c|c|c|c|c|c|c|c|}
\hline & \multicolumn{2}{|c|}{ All } & \multicolumn{2}{|c|}{$\begin{array}{c}\text { Men } \\
(n 350)\end{array}$} & \multicolumn{2}{|c|}{$\begin{array}{l}\text { Women } \\
(n 731)\end{array}$} & \multicolumn{2}{|c|}{$\begin{array}{l}\text { Breast cancer } \\
\qquad(n 382)\end{array}$} & \multicolumn{2}{|c|}{$\begin{array}{c}\text { Prostate } \\
\text { cancer } \\
(n 168)\end{array}$} \\
\hline & $n$ & $\%$ & $n$ & $\%$ & $n$ & $\%$ & $n$ & $\%$ & $n$ & $\%$ \\
\hline $\begin{array}{l}\text { DS use after cancer diagnosis* }{ }^{*} \text { yes) } \\
\text { Specific DS use in users } \dagger\end{array}$ & 556 & $51 \cdot 4$ & 101 & $28 \cdot 9$ & 455 & $62 \cdot 2$ & 261 & $68 \cdot 3$ & 48 & $28 \cdot 6$ \\
\hline Vitamin D & 251 & $45 \cdot 1$ & 34 & $33 \cdot 7$ & 217 & $47 \cdot 7$ & 128 & 48.9 & 19 & $39 \cdot 6$ \\
\hline Vitamin $\mathrm{B}_{6}$ & 209 & $37 \cdot 6$ & 40 & $39 \cdot 6$ & 169 & $37 \cdot 1$ & 94 & 35.9 & 19 & $39 \cdot 6$ \\
\hline $\mathrm{Mg}$ & 184 & $33 \cdot 1$ & 35 & $34 \cdot 7$ & 149 & $32 \cdot 7$ & 85 & $32 \cdot 4$ & 21 & $43 \cdot 8$ \\
\hline Vitamin C & 175 & 31.5 & 41 & $40 \cdot 6$ & 134 & 29.5 & 79 & $30 \cdot 2$ & 21 & $43 \cdot 8$ \\
\hline $\mathrm{Zn}$ & 161 & $29 \cdot 0$ & 33 & $32 \cdot 7$ & 128 & $28 \cdot 1$ & 76 & $29 \cdot 0$ & 15 & $31 \cdot 3$ \\
\hline Vitamin $\mathrm{E}$ & 159 & 28.6 & 34 & 33.7 & 125 & 27.5 & 72 & 27.5 & 18 & 37.5 \\
\hline Folate & 145 & $26 \cdot 1$ & 32 & 31.7 & 113 & $24 \cdot 8$ & 60 & 22.9 & 15 & $31 \cdot 3$ \\
\hline Thiamin & 138 & $24 \cdot 8$ & 31 & 30.7 & 107 & 23.5 & 60 & 22.9 & 16 & $33 \cdot 3$ \\
\hline Riboflavin & 136 & 24.5 & 32 & 31.7 & 104 & 22.9 & 60 & 22.9 & 17 & 35.4 \\
\hline Niacin & 134 & $24 \cdot 1$ & 30 & 29.7 & 104 & 22.9 & 61 & $23 \cdot 3$ & 16 & $33 \cdot 3$ \\
\hline $\mathrm{Ca}$ & 122 & 21.9 & 21 & $20 \cdot 8$ & 101 & $22 \cdot 2$ & 53 & $20 \cdot 2$ & 13 & $27 \cdot 1$ \\
\hline $\mathrm{Se}$ & 115 & $20 \cdot 7$ & 23 & $22 \cdot 8$ & 92 & $20 \cdot 2$ & 54 & $20 \cdot 6$ & 11 & 22.9 \\
\hline $\mathrm{Fe}$ & 114 & $20 \cdot 5$ & 26 & $25 \cdot 7$ & 88 & $19 \cdot 3$ & 45 & $17 \cdot 2$ & 12 & $25 \cdot 0$ \\
\hline Pantothenic acid & 108 & $19 \cdot 4$ & 22 & $21 \cdot 8$ & 86 & $18 \cdot 9$ & 50 & $19 \cdot 1$ & 11 & $22 \cdot 9$ \\
\hline Vitamin $\mathrm{B}_{12}$ & 91 & $16 \cdot 4$ & 25 & $24 \cdot 8$ & 66 & 14.5 & 32 & $12 \cdot 2$ & 11 & 22.9 \\
\hline Vitamin $B_{8}$ & 91 & $16 \cdot 4$ & 18 & $17 \cdot 8$ & 73 & $16 \cdot 0$ & 38 & 14.5 & 7 & $14 \cdot 6$ \\
\hline Polyphenols & 81 & $14 \cdot 6$ & 18 & $17 \cdot 8$ & 63 & $13 \cdot 8$ & 39 & $14 \cdot 9$ & 9 & $18 \cdot 8$ \\
\hline Acerola, guarana or cranberry & 74 & $13 \cdot 3$ & 12 & 11.9 & 62 & $13 \cdot 6$ & 35 & $13 \cdot 4$ & 3 & $6 \cdot 3$ \\
\hline Fibre & 72 & $12 \cdot 9$ & 15 & $14 \cdot 9$ & 57 & $12 \cdot 5$ & 43 & $16 \cdot 4$ & 8 & $16 \cdot 7$ \\
\hline Probiotics & 71 & $12 \cdot 8$ & 9 & 8.9 & 62 & $13 \cdot 6$ & 42 & $16 \cdot 0$ & 2 & $4 \cdot 2$ \\
\hline Amino acids/proteins & 68 & $12 \cdot 2$ & 13 & $12 \cdot 9$ & 55 & $12 \cdot 1$ & 32 & $12 \cdot 2$ & 3 & $6 \cdot 3$ \\
\hline Phyto-oestrogen & 64 & 11.5 & 16 & $15 \cdot 8$ & 48 & $10 \cdot 5$ & 26 & 9.9 & 8 & $16 \cdot 7$ \\
\hline Retinol & 61 & $11 \cdot 0$ & 9 & 8.9 & 52 & $11 \cdot 4$ & 30 & 11.5 & 4 & $8 \cdot 3$ \\
\hline$n-3$ Fatty acids & 56 & $10 \cdot 1$ & 15 & 14.9 & 41 & $9 \cdot 0$ & 28 & $10 \cdot 7$ & 9 & $18 \cdot 8$ \\
\hline I & 55 & 9.9 & 11 & $10 \cdot 9$ & 44 & $9 \cdot 7$ & 23 & $8 \cdot 8$ & 4 & $8 \cdot 3$ \\
\hline$\beta$-Carotene & 46 & $8 \cdot 3$ & 9 & 8.9 & 37 & $8 \cdot 1$ & 19 & $7 \cdot 3$ & 4 & $8 \cdot 3$ \\
\hline $\mathrm{P}$ & 43 & $7 \cdot 7$ & 9 & $8 \cdot 9$ & 34 & $7 \cdot 5$ & 21 & $8 \cdot 0$ & 3 & $6 \cdot 3$ \\
\hline Desmodium & 40 & $7 \cdot 2$ & 2 & $2 \cdot 0$ & 38 & $8 \cdot 4$ & 28 & $10 \cdot 7$ & 1 & $2 \cdot 1$ \\
\hline $\begin{array}{l}\text { Evening primrose, borage, } \\
\text { or cod liver oil }\end{array}$ & 33 & 5.9 & 1 & $1 \cdot 0$ & 32 & $7 \cdot 0$ & 23 & $8 \cdot 8$ & 1 & $2 \cdot 1$ \\
\hline Ginseng & 33 & $5 \cdot 9$ & 8 & 7.9 & 25 & $5 \cdot 5$ & 9 & $3 \cdot 4$ & 2 & $4 \cdot 2$ \\
\hline Lutein & 31 & $5 \cdot 6$ & 14 & $13 \cdot 9$ & 17 & $3 \cdot 7$ & 7 & $2 \cdot 7$ & 6 & $12 \cdot 5$ \\
\hline Zeaxanthin & 13 & $2 \cdot 3$ & 6 & 5.9 & 7 & 1.5 & 3 & $1 \cdot 1$ & 3 & $6 \cdot 3$ \\
\hline Flaxseed oil & 13 & $2 \cdot 3$ & 3 & $3 \cdot 0$ & 10 & $2 \cdot 2$ & 5 & 1.9 & 3 & $6 \cdot 3$ \\
\hline Red yeast rice & 10 & $1 \cdot 8$ & 3 & $3 \cdot 0$ & 7 & 1.5 & 3 & $1 \cdot 1$ & 1 & $2 \cdot 1$ \\
\hline Lycopene & 9 & $1 \cdot 6$ & 1 & $1 \cdot 0$ & 8 & $1 \cdot 8$ & 6 & $2 \cdot 3$ & 0 & 0.0 \\
\hline Echinacea & 7 & $1 \cdot 3$ & 1 & $1 \cdot 0$ & 6 & $1 \cdot 3$ & 4 & 1.5 & 1 & $2 \cdot 1$ \\
\hline Vitamin $\mathrm{K}$ & 5 & 0.9 & 2 & $2 \cdot 0$ & 3 & 0.7 & 0 & 0.0 & 2 & $4 \cdot 2$ \\
\hline Dehydroepiandrosterone & 4 & 0.7 & 0 & 0.0 & 4 & 0.9 & 1 & 0.4 & 0 & 0.0 \\
\hline Phytoprogestagen & 4 & 0.7 & 0 & 0.0 & 4 & 0.9 & 3 & $1 \cdot 1$ & 0 & 0.0 \\
\hline Fluoride & 4 & 0.7 & 0 & 0.0 & 4 & 0.9 & 4 & 1.5 & 0 & 0.0 \\
\hline Alfalfa & 3 & 0.5 & 0 & 0.0 & 3 & 0.7 & 3 & $1 \cdot 1$ & 0 & 0.0 \\
\hline Black cohosh & 1 & 0.2 & 0 & 0.0 & 1 & 0.2 & 0 & 0.0 & 0 & 0.0 \\
\hline Other minerals $\ddagger$ & 121 & $21 \cdot 8$ & 28 & $27 \cdot 7$ & 93 & $20 \cdot 4$ & 59 & $22 \cdot 5$ & 16 & $33 \cdot 3$ \\
\hline Other herbal supplements & 34 & $6 \cdot 1$ & 7 & 6.9 & 27 & 5.9 & 12 & $4 \cdot 6$ & 4 & $8 \cdot 3$ \\
\hline
\end{tabular}

${ }^{*}$ At least one DS taken after cancer diagnosis.

$\dagger$ In decreasing order of frequency. Nutrients and other substances were consumed alone or in combination in a single DS. Percentages were calculated among overall DS users.

$\ddagger \mathrm{K}, \mathrm{Cu}, \mathrm{Li}, \mathrm{Mn}, \mathrm{Cr}$ and others. 
not classified as under-reporters of energy intake according to the Black $^{(38)}$ criteria (eighty-five subjects excluded) were included in dietary data analyses ( $n$ 668). Most participants provided three $24 \mathrm{~h}$ dietary records, but $7 \%$ provided two records. The mean daily intake of dietary macro- and micronutrients from food only and from food and supplements were compared by unconditional logistic regression between DS users and non-users after adjustment for age, sex, number of $24 \mathrm{~h}$ dietary records and energy intake. The aim of the present analysis was to quantify the extent to which total nutrient intake increased when total intake from food and supplements was considered in comparison to intake from food only and which nutrients were more specifically impacted. For each nutrient, the proportion of total daily intake brought by DS was also estimated both in overall DS users and in DS users of the specific nutrient. The number of subjects who practised potentially harmful DS use was assessed. Such practices included: (1) use of $\beta$-carotene DS by smokers ${ }^{(5,10,11)}$; (2) the use of DS that should be avoided in certain cancer patients, such as phyto-oestrogen use by hormone-dependent cancer patients $^{(6,9)}$; and (3) the simultaneous use of DS (current use at the time of the DS and medication questionnaire) and drugs for which harmful interactions of moderate-to-major severity have been described in the literature ${ }^{(9,13-15)}$.

$P<0.05$ was considered statistically significant. All tests were two-sided. Analyses were carried out with SAS software release 9.3 (SAS Institute, Inc.).

\section{Results}

A total of 1490 subjects developed an incident primary cancer between the beginning of the study and January 2014. Among them, 1081 answered the DS questionnaire (participation rate $=73 \%$ ). The average age of cancer survivors was $60 \cdot 2$ (SD 10.9) years. Women constituted $68 \%$ of the sample. The main cancer types were breast $(43 \%)$, followed by prostate (19\%) and melanoma skin cancer (15\%). The mean time between cancer diagnosis and administration of the DS questionnaire was 22.3 (SD 14.6) months.

Table 2. Reasons for dietary supplement (DS) use in cancer survivors ( $n$ 522, NutriNet-Santé study, 2014)

(Number of subjects and percentages)

\begin{tabular}{|c|c|c|c|c|c|c|c|c|c|c|}
\hline & \multicolumn{2}{|c|}{ All } & \multicolumn{2}{|c|}{$\begin{array}{c}\text { Men } \\
(n 97)\end{array}$} & \multicolumn{2}{|c|}{$\begin{array}{l}\text { Women } \\
(n \text { 425) }\end{array}$} & \multicolumn{2}{|c|}{$\begin{array}{l}\text { Breast } \\
\text { cancer } \\
(n 246)\end{array}$} & \multicolumn{2}{|c|}{$\begin{array}{c}\text { Prostate } \\
\text { cancer } \\
(n 46)\end{array}$} \\
\hline & $n$ & $\%$ & $n$ & $\%$ & $n$ & $\%$ & $n$ & $\%$ & $n$ & $\%$ \\
\hline \multicolumn{11}{|l|}{ Reasons for DS use* } \\
\hline Fight against cancer & 249 & $47 \cdot 7$ & 41 & $42 \cdot 3$ & 208 & $48 \cdot 9$ & 140 & $56 \cdot 9$ & 20 & 43.5 \\
\hline Reduce adverse effects of cancer treatments & 147 & $28 \cdot 2$ & 12 & 12.4 & 133 & $31 \cdot 3$ & 101 & $41 \cdot 1$ & 4 & $8 \cdot 7$ \\
\hline Fight against recurrences & 72 & $13 \cdot 8$ & 15 & $15 \cdot 5$ & 57 & 13.4 & 41 & $16 \cdot 7$ & 8 & $17 \cdot 4$ \\
\hline Manage my disease & 53 & $10 \cdot 2$ & 15 & $15 \cdot 5$ & 38 & $8 \cdot 9$ & 22 & $8 \cdot 9$ & 9 & $19 \cdot 6$ \\
\hline Reduce symptoms & 45 & $8 \cdot 6$ & 8 & $8 \cdot 2$ & 37 & $8 \cdot 7$ & 27 & $11 \cdot 0$ & 3 & 6.5 \\
\hline Other reason related to cancer & 42 & $8 \cdot 0$ & 14 & $14 \cdot 4$ & 37 & $8 \cdot 7$ & 18 & $7 \cdot 3$ & 2 & $4 \cdot 3$ \\
\hline Other health problems (other than cancer) & 432 & $82 \cdot 8$ & 82 & 84.5 & 350 & 82.4 & 202 & $82 \cdot 1$ & 40 & $87 \cdot 0$ \\
\hline Strengthen immune system & 281 & $53 \cdot 8$ & 56 & $57 \cdot 7$ & 225 & 52.9 & 130 & $52 \cdot 8$ & 30 & $65 \cdot 2$ \\
\hline Solve or fight against health problems & 191 & $36 \cdot 6$ & 32 & $33 \cdot 0$ & 159 & $37 \cdot 4$ & 83 & $33 \cdot 7$ & 17 & $37 \cdot 0$ \\
\hline Prevent diseases & 78 & 14.9 & 18 & $18 \cdot 6$ & 60 & $14 \cdot 1$ & 33 & $13 \cdot 4$ & 9 & $19 \cdot 6$ \\
\hline Other reason related to health problem & 60 & 11.5 & 8 & $8 \cdot 2$ & 52 & $12 \cdot 2$ & 34 & $13 \cdot 8$ & 4 & $8 \cdot 7$ \\
\hline Improve my well-being & 311 & $59 \cdot 6$ & 60 & 61.9 & 251 & $59 \cdot 1$ & 151 & 61.4 & 30 & $65 \cdot 2$ \\
\hline Overcome tiredness & 202 & $38 \cdot 7$ & 41 & $42 \cdot 3$ & 161 & $37 \cdot 9$ & 92 & $37 \cdot 4$ & 20 & 43.5 \\
\hline Counter stress & 67 & $12 \cdot 8$ & 7 & $7 \cdot 2$ & 60 & $14 \cdot 1$ & 29 & $11 \cdot 8$ & 3 & $6 \cdot 5$ \\
\hline Sleeping & 54 & $10 \cdot 3$ & 3 & $3 \cdot 1$ & 51 & $12 \cdot 0$ & 31 & $12 \cdot 6$ & 1 & $2 \cdot 2$ \\
\hline Relieve female disorders related to menopause & 45 & $8 \cdot 6$ & 0 & 0.0 & 45 & $10 \cdot 6$ & 30 & $12 \cdot 2$ & 0 & 0.0 \\
\hline Digestion, intestinal comfort & 31 & $5 \cdot 9$ & 6 & $6 \cdot 2$ & 27 & 6.4 & 14 & $5 \cdot 7$ & 2 & $4 \cdot 3$ \\
\hline Circulation & 23 & 4.4 & 5 & $5 \cdot 2$ & 18 & $4 \cdot 2$ & 9 & $3 \cdot 7$ & 3 & $6 \cdot 5$ \\
\hline Relieve female disorders related to premenstrual syndrome & 2 & 0.4 & 0 & 0.0 & 2 & 0.5 & 1 & 0.4 & 0 & 0.0 \\
\hline Other reason related to the well-being & 82 & $15 \cdot 7$ & 19 & $19 \cdot 6$ & 63 & $14 \cdot 8$ & 39 & $15 \cdot 9$ & 10 & $21 \cdot 7$ \\
\hline Fill in special needs & 178 & $34 \cdot 1$ & 44 & $45 \cdot 4$ & 134 & 31.5 & 78 & $31 \cdot 7$ & 25 & $54 \cdot 3$ \\
\hline Compensate inadequate dietary intake associated with a restrictive diet & 75 & 14.4 & 21 & $21 \cdot 6$ & 54 & $12 \cdot 7$ & 30 & $12 \cdot 2$ & 12 & $26 \cdot 1$ \\
\hline Compensate dietary intake perceived as inadequate (without restrictive diet) & 65 & $12 \cdot 5$ & 10 & $10 \cdot 3$ & 55 & $12 \cdot 9$ & 33 & $13 \cdot 4$ & 8 & $17 \cdot 4$ \\
\hline Fill in special needs related to sport practice & 47 & $9 \cdot 0$ & 17 & $17 \cdot 5$ & 30 & $7 \cdot 1$ & 19 & $7 \cdot 7$ & 10 & $21 \cdot 7$ \\
\hline Fill in special needs related to pregnancy & 4 & 0.8 & 0 & 0.0 & 4 & 0.9 & 0 & 0.0 & 0 & 0.0 \\
\hline Improve my appearance and performance & 221 & $42 \cdot 3$ & 48 & $49 \cdot 5$ & 173 & $40 \cdot 7$ & 111 & $45 \cdot 1$ & 27 & $58 \cdot 7$ \\
\hline Age well & 131 & $25 \cdot 1$ & 38 & $39 \cdot 2$ & 93 & 21.9 & 54 & $22 \cdot 0$ & 24 & $52 \cdot 2$ \\
\hline Beauty & 75 & 14.4 & 6 & $6 \cdot 2$ & 69 & $16 \cdot 2$ & 46 & $18 \cdot 7$ & 2 & $4 \cdot 3$ \\
\hline Improve intellectual performance & 31 & 5.9 & 7 & $7 \cdot 2$ & 24 & $5 \cdot 6$ & 17 & $6 \cdot 9$ & 3 & $6 \cdot 5$ \\
\hline Stay young & 12 & $2 \cdot 3$ & 8 & $8 \cdot 2$ & 4 & 0.9 & 3 & $1 \cdot 2$ & 4 & $8 \cdot 7$ \\
\hline Lose weight & 10 & 1.9 & 1 & $1 \cdot 0$ & 9 & $2 \cdot 1$ & 6 & $2 \cdot 4$ & 0 & $0 \cdot 0$ \\
\hline Act on my silhouette & 10 & 1.9 & 0 & 0.0 & 10 & $2 \cdot 4$ & 6 & $2 \cdot 4$ & 0 & $0 \cdot 0$ \\
\hline Improve sexual performance & 1 & $0 \cdot 2$ & 1 & $1 \cdot 0$ & 0 & 0.0 & 0 & 0.0 & 0 & 0.0 \\
\hline Put on weight & 0 & 0.0 & 0 & 0.0 & 0 & 0.0 & 0 & 0.0 & 0 & $0 \cdot 0$ \\
\hline Other reason related to my appearance or performance & 30 & $5 \cdot 7$ & 4 & $4 \cdot 1$ & 26 & $6 \cdot 1$ & 15 & $6 \cdot 1$ & 2 & $4 \cdot 3$ \\
\hline
\end{tabular}

${ }^{*}$ At least one DS taken after cancer diagnosis. Data regarding reasons for DS use were missing for thirty-four DS users. Several answers were possible. 


\section{Overall and specific dietary supplement use}

DS use by sex and among breast and prostate cancer survivors is presented in Table 1. $62 \%$ of women $(n$ 455) and $29 \%$ of men ( $n$ 101) reported using at least one DS after cancer diagnosis ( $n 556$ in all): 442 were current users (at the time of the DS questionnaire), and 114 had taken DS since their cancer diagnosis but were not currently using DS. In current users, the number of DS taken simultaneously was 1,2 or $\geq 3$ in 52, 24 and $24 \%$ of the subjects, respectively. The mean number of DS taken was 1.9 (SD 1.4). Vitamin D, vitamin $\mathrm{B}_{6}$, $\mathrm{Mg}$ and vitamin $\mathrm{C}$ were the most frequently used DS nutrients. After cancer diagnosis, $14 \%$ of subjects started DS use, $9 \% \mathrm{kept}$ using DS but modified the types of DS used and $4 \%$ stopped using DS (data not tabulated).

\section{Motivations for dietary supplement use, circumstances of} purchase and involvement of attending physicians

The main stated reasons for DS use included: to reduce the adverse effects of cancer treatments (28.2\%), to decrease the risk of cancer recurrence $(13.8 \%)$, to strengthen the immune system (54\%), and to overcome tiredness (39\%) (Table 2, several answers possible). Similar motivations were reported by men and women and for breast and prostate cancer patients. study, France, 2014)

(Number of subjects and percentages)
Among the 1140 DS reported by the participants, only about half of them $(54 \%)$ were taken following medical prescription or advice (Table 3). Medical prescription or advice was higher for vitamin D DS (81\%), medium for many vitamins and minerals (e.g. $43 \%$ for vitamin $\mathrm{C}$ and $\mathrm{Mg}$ and $47 \%$ for vitamin $\mathrm{B}_{6}$ ) and lower for herbal/natural DS (36\% for acerola/guarana and $24 \%$ for phyto-oestrogen DS) (data not tabulated). Among the 1140 DS reported, 56\% were used for more than 1 year. For $35 \%$ of reported DS, participants did not inform any of their attending physicians (general practitioner, oncologist or other) about their use. The main reason cited for this was that physicians did not ask their patients about their DS use (86\%).

\section{Sociodemographic, lifestyle and anthropometric correlates of dietary supplement use}

As compared to non-users (Table 4), DS users were more likely to be women $(P<0 \cdot 0001)$ those with higher educational levels $(P=0.0001)$, never smokers $(P=0.03)$ and those with a normal weight $(P=0.0005)$.

\section{Dietary correlates of dietary supplement use and its contribution to nutrient intake}

When considering food intake only (Table 5), DS users already had significantly higher intakes of fibre, vitamins $B_{6}$,

Table 3. Circumstances of purchase, duration of use, and communication with the attending physician for the 1140 dietary supplements (DS) reported by cancer survivors (NutriNet-Santé cohort

\begin{tabular}{|c|c|c|}
\hline & Number of DS ( $n 1140)$ & $\%$ \\
\hline \multicolumn{3}{|l|}{ Circumstances of DS purchase* } \\
\hline On medical prescription & 451 & 39.6 \\
\hline On medical advice (without prescription) & 168 & $14 \cdot 7$ \\
\hline Discovered the DS in-store by themselves & 141 & $12 \cdot 4$ \\
\hline On the advice of a pharmacist & 111 & $9 \cdot 7$ \\
\hline On the advice of a friend/family member & 105 & $9 \cdot 2$ \\
\hline On the advice of another health professional & 64 & $5 \cdot 6$ \\
\hline Heard of the DS from the media (television, magazine, etc.) & 47 & $4 \cdot 1$ \\
\hline Heard of the DS from a book & 46 & 4.0 \\
\hline Saw an advertisement & 31 & $2 \cdot 7$ \\
\hline On the advice of a dietitian & 25 & $2 \cdot 2$ \\
\hline On the advice of another patient & 20 & 1.8 \\
\hline On advice received in-store (except chemistry) & 12 & $1 \cdot 1$ \\
\hline On the advice of a physical activity professional & 8 & 0.7 \\
\hline Other circumstances & 40 & 3.5 \\
\hline \multicolumn{3}{|l|}{ Duration of DS use (years) } \\
\hline$<1$ & 506 & 44.4 \\
\hline $1-2$ & 283 & 24.8 \\
\hline $3-5$ & 210 & 18.5 \\
\hline $5-10$ & 86 & 7.5 \\
\hline$>10$ & 55 & 4.8 \\
\hline \multicolumn{3}{|l|}{ Have you informed one of your physicianst about this DS use? } \\
\hline Yes & 742 & $65 \cdot 1$ \\
\hline No & 398 & 34.9 \\
\hline \multicolumn{3}{|l|}{ Reasons for not informing the physician $\ddagger$} \\
\hline He did not ask & 343 & $86 \cdot 2$ \\
\hline He does not need to know & 85 & 21.4 \\
\hline He could not understand & 41 & $10 \cdot 3$ \\
\hline He would disapprove & 17 & $4 \cdot 3$ \\
\hline
\end{tabular}

* Several answers were possible.

† General practitioner, oncologist or other attending physician

$\ddagger$ Among the 398 DS for which participants answered 'no' to the previous question. Several answers were possible. 
Table 4. Sociodemographic, lifestyle and behavioural correlates of dietary supplement (DS) use in cancer survivors ( $n$ 1081, NutriNet-Santé cohort study, France, 2014)

(Number of subjects, percentages, odds ratios and $95 \%$ confidence intervals)

\begin{tabular}{|c|c|c|c|c|c|c|c|}
\hline & \multicolumn{2}{|c|}{ All $(n$ 1081) } & \multicolumn{2}{|c|}{$\begin{array}{l}\text { Percentage of } \\
\text { DS users in } \\
\text { each category* } \\
\quad(n 524)\end{array}$} & \multicolumn{3}{|c|}{$\begin{array}{l}\text { Age and sex adjusted } \\
\text { logistic regression analyses }\end{array}$} \\
\hline & $n$ & $\%$ & $n$ & $\%$ & OR & $95 \% \mathrm{Cl}$ & $P$ \\
\hline Sex & & & & & & & $<0.0001$ \\
\hline Male & 350 & $32 \cdot 38$ & 101 & 28.9 & 1.00 & & \\
\hline Female & 731 & 67.62 & 455 & $62 \cdot 2$ & 4.24 & $3 \cdot 15,5 \cdot 71$ & \\
\hline Age (years) & & & & & & & 0.2 \\
\hline$<55$ & 306 & $28 \cdot 31$ & 170 & $55 \cdot 6$ & 1.00 & & \\
\hline $55-65$ & 387 & $35 \cdot 80$ & 215 & $55 \cdot 6$ & 1.32 & $0.96,1.81$ & \\
\hline$>65$ & 388 & $35 \cdot 89$ & 171 & $44 \cdot 1$ & $1 \cdot 17$ & $0.83,1.64$ & \\
\hline Geographical region & & & & & & & 0.9 \\
\hline Paris suburb & 236 & 21.83 & 125 & $53 \cdot 0$ & 1.00 & & \\
\hline North-North East & 147 & $13 \cdot 60$ & 70 & $47 \cdot 6$ & 0.84 & $0.55,1.30$ & \\
\hline North-West & 194 & 17.95 & 94 & 48.5 & 0.85 & $0.57,1.27$ & \\
\hline South-West & 122 & 11.29 & 67 & 54.9 & 1.07 & $0.68,1.70$ & \\
\hline Centre & 229 & $21 \cdot 18$ & 123 & $53 \cdot 7$ & 1.02 & $0.69,1.49$ & \\
\hline South-East & 146 & 13.51 & 73 & $50 \cdot 0$ & 0.97 & $0.63,1.50$ & \\
\hline Others $†$ & 7 & 0.65 & 4 & $57 \cdot 1$ & 1.48 & $0.29,7.43$ & \\
\hline Marital status & & & & & & & 0.8 \\
\hline Married or with partner & 802 & $74 \cdot 19$ & 394 & $49 \cdot 1$ & 1.00 & & \\
\hline Divorced/separated/widowed & 189 & $17 \cdot 48$ & 108 & $57 \cdot 1$ & $1 \cdot 10$ & $0.78,1.54$ & \\
\hline Single & 90 & 8.33 & 54 & $60 \cdot 0$ & 1.14 & $0.72,1.82$ & \\
\hline Children & & & & & & & 0.09 \\
\hline Yes & 367 & 33.95 & 176 & $48 \cdot 0$ & 1.00 & & \\
\hline No & 714 & $66 \cdot 05$ & 380 & $53 \cdot 2$ & 0.79 & $0.61,1.04$ & \\
\hline Education & & & & & & & 0.0001 \\
\hline$\leq 12$ years of schooling & 468 & $43 \cdot 29$ & 207 & $44 \cdot 2$ & 1.00 & & \\
\hline$>12$ years of schooling & 613 & $56 \cdot 71$ & 349 & $56 \cdot 9$ & 1.66 & $1 \cdot 29,2 \cdot 15$ & \\
\hline Smoking status & & & & & & & 0.03 \\
\hline Never smoker & 436 & $40 \cdot 33$ & 249 & $57 \cdot 1$ & 1.00 & & \\
\hline Former smoker & 523 & $48 \cdot 38$ & 255 & $48 \cdot 8$ & 0.57 & $0.37,0.87$ & \\
\hline Current smoker & 122 & $11 \cdot 29$ & 52 & $42 \cdot 6$ & 0.90 & $0.68,1.18$ & \\
\hline $\mathrm{BMI}\left(\mathrm{kg} / \mathrm{m}^{2}\right)$ & & & & & & & 0.0005 \\
\hline Normal weight (18.5-24.9) & 620 & $57 \cdot 35$ & 364 & $58 \cdot 7$ & 1.00 & & \\
\hline Underweight $(<18.5)$ & 28 & 2.59 & 17 & $60 \cdot 7$ & 0.75 & $0.34,1.64$ & \\
\hline Overweight and obese $(\geq 25)$ & 433 & $40 \cdot 06$ & 175 & $40 \cdot 4$ & 0.59 & $0.45,0.77$ & \\
\hline Leisure physical activity $\ddagger$ & & & & & & & 0.2 \\
\hline High & 350 & 39.64 & 167 & $47 \cdot 7$ & 1.00 & & \\
\hline Moderate & 328 & $37 \cdot 15$ & 185 & $56 \cdot 4$ & $1 \cdot 31$ & $0.95,1.81$ & \\
\hline Low & 205 & $23 \cdot 22$ & 107 & $52 \cdot 2$ & $1 \cdot 12$ & $0.77,1.62$ & \\
\hline
\end{tabular}

${ }^{*}$ At least one DS taken after cancer diagnosis.

†Overseas departments/territories.

$\ddagger$ As measures by the international physical activity questionnaire. Because of missing values, the proportions of subjects were calculated on 883 participants (459 DS users and 424 non-users).

$\mathrm{B}_{9}$ and $\mathrm{C}, \mathrm{Fe}, \mathrm{Mg}, \mathrm{K}$ and $\mathrm{Zn}$. When considering total intake (food + DS), DS users additionally had higher intakes of thiamin, riboflavin, niacin, pantothenic acid, vitamins D and $\mathrm{E}$ and $\mathrm{Ca}$ compared to non-users.

The contribution of DS to total nutrient intake was very high for some nutrients: in DS users of the specific nutrient, DS represented more than half of the total daily intakes for vitamins $\mathrm{D}(89 \%), \mathrm{B}_{6}(68 \%), \mathrm{E}(68 \%)$ and $\mathrm{B}_{12}(50 \%)$ and more than one-third of the total daily intake for fibre, thiamin, pantothenic acid, folate, retinol, vitamin $\mathrm{C}$ and $\mathrm{Ca}$.

\section{Potentially harmful dietary supplement use practices}

Among the 442 DS current users (i.e. participants who were using DS at the time of the DS and medication questionnaire), eightyone (18\%) reported DS practices that were contraindicated because of potential for adverse effects documented in the literature. Such practices are listed in Table 6 (one patient may cumulate several of these practices): thirty participants with smoking history (six current and twenty-four former smokers) used $\beta$-carotene DS, forty-four participants used DS that were contraindicated for specific cancer sites and thirty-nine participants simultaneously used DS and drugs for which a drugnutrient interaction of moderate-to-major severity would be predicted.

\section{Discussion}

DS use was widespread in the present large sample of French cancer patients or survivors (29\% of men and $62 \%$ of women). These proportions were lower than those observed in various American studies (50 to $81 \%$ DS users) $)^{(16,18,39)}$ 
Table 5. Comparison of daily dietary energy and nutrient intakes from food only and from food and dietary supplements (DS), between DS users ( $n$ 270) and non-users ( $n$ 398) among cancer survivors (NutriNet-Santé cohort study, France, 2014)*

(Mean values, standard errors, number of subjects and percentages)

\begin{tabular}{|c|c|c|c|c|c|c|c|c|c|c|c|}
\hline & \multicolumn{5}{|c|}{ Food only } & \multicolumn{6}{|c|}{ Food + supplements } \\
\hline & \multicolumn{2}{|c|}{ Non-users } & \multicolumn{2}{|c|}{ Users } & \multirow[b]{2}{*}{$P \dagger$} & \multicolumn{4}{|c|}{ Overall DS users } & \multicolumn{2}{|c|}{ Specific DS users } \\
\hline & $\begin{array}{c}\text { Mean daily } \\
\text { nutrient intake }\end{array}$ & SE & $\begin{array}{c}\text { Mean daily } \\
\text { nutrient intake }\end{array}$ & SE & & $\begin{array}{c}\text { Mean daily } \\
\text { nutrient intake }\end{array}$ & SE & $P \dagger$ & $\%$ from DS & $n$ & $\%$ from DS \\
\hline Energy & & & & & 0.4 & & & 0.3 & & 270 & \\
\hline kcal & $2096 \cdot 7$ & 37.8 & $2129 \cdot 8$ & 43.4 & & $2133 \cdot 8$ & 43.4 & & 0.2 & & 0.2 \\
\hline $\mathrm{kJ}$ & 8773 & $158 \cdot 2$ & $8911 \cdot 1$ & 181.6 & & $8927 \cdot 8$ & $181 \cdot 6$ & & 0.8 & & 0.8 \\
\hline Alcohol (g)‡ & $12 \cdot 2$ & $1 \cdot 1$ & $11 \cdot 1$ & $1 \cdot 2$ & 0.3 & $11 \cdot 1$ & $1 \cdot 2$ & 0.3 & 0.0 & 3 & $18 \cdot 6$ \\
\hline Total carbohydrates (g) & $192 \cdot 4$ & 3.0 & 193.6 & 3.4 & 0.7 & 193.9 & 3.4 & 0.6 & 0.2 & 91 & 0.5 \\
\hline Simple carbohydrates (g) & 88.9 & $2 \cdot 4$ & $92 \cdot 3$ & $2 \cdot 7$ & 0.1 & $92 \cdot 3$ & $2 \cdot 7$ & 0.1 & 0.0 & 45 & 0.3 \\
\hline Starch $(g)$ & $102 \cdot 9$ & $2 \cdot 4$ & $100 \cdot 6$ & $2 \cdot 8$ & 0.3 & $100 \cdot 6$ & $2 \cdot 8$ & 0.3 & 0.0 & 0 & 0.0 \\
\hline Fibre $(\mathrm{g})$ & 19.3 & 0.6 & $21 \cdot 3$ & 0.6 & 0.0002 & 24.9 & 1.2 & 0.0001 & 14.5 & 42 & $38 \cdot 0$ \\
\hline Proteins (g) & $85 \cdot 3$ & 1.2 & $85 \cdot 7$ & 1.4 & 0.8 & $87 \cdot 8$ & $2 \cdot 0$ & 0.1 & $2 \cdot 4$ & 79 & $11 \cdot 1$ \\
\hline Total lipids (g) & $82 \cdot 2$ & 1.2 & $82 \cdot 3$ & 1.4 & 0.9 & $82 \cdot 4$ & 1.4 & 0.9 & $0 \cdot 1$ & 84 & 0.1 \\
\hline SFA (g) & $32 \cdot 6$ & 0.7 & 31.9 & 0.8 & 0.3 & 31.9 & 0.8 & 0.3 & 0.0 & 44 & 0.0 \\
\hline MUFA (g) & $31 \cdot 6$ & 0.6 & $32 \cdot 2$ & 0.7 & 0.2 & $32 \cdot 2$ & 0.7 & 0.3 & 0.0 & 13 & 0.0 \\
\hline PUFA (g) & 11.4 & 0.3 & 11.7 & 0.4 & 0.4 & 11.7 & 0.4 & 0.3 & 0.0 & 65 & 3.3 \\
\hline Thiamin (mg) & $1 \cdot 2$ & 0.0 & $1 \cdot 2$ & 0.0 & 0.5 & 1.4 & 0.1 & $<0.0001$ & $14 \cdot 3$ & 97 & $36 \cdot 8$ \\
\hline Riboflavin (mg) & 1.9 & 0.0 & 1.9 & 0.1 & 0.9 & $2 \cdot 1$ & 0.1 & 0.02 & 9.5 & 96 & $26 \cdot 9$ \\
\hline Niacin $(\mathrm{mg})$ & $20 \cdot 7$ & 0.5 & $21 \cdot 3$ & 0.5 & 0.2 & $23 \cdot 1$ & 0.6 & 0.0001 & $7 \cdot 8$ & 97 & $22 \cdot 8$ \\
\hline Pantothenic acid (mg) & $5 \cdot 7$ & $0 \cdot 1$ & $5 \cdot 8$ & 0.1 & 0.3 & 6.5 & 0.2 & $<0.0001$ & $10 \cdot 8$ & 80 & $34 \cdot 1$ \\
\hline Vitamin $B_{6}(\mathrm{mg})$ & 1.8 & 0.0 & $2 \cdot 0$ & 0.0 & 0.001 & 3.6 & 0.8 & $<0.0001$ & 44.4 & 151 & $68 \cdot 3$ \\
\hline Folate $(\mu \mathrm{g})$ & 335.2 & $9 \cdot 4$ & 354.6 & $10 \cdot 8$ & 0.03 & 468.7 & $21 \cdot 8$ & $<0.0001$ & $24 \cdot 3$ & 110 & 37.9 \\
\hline Vitamin $B_{12}(\mu \mathrm{g})$ & 7.5 & 0.5 & $7 \cdot 2$ & 0.6 & 0.6 & 8.3 & $1 \cdot 1$ & 0.4 & $13 \cdot 3$ & 65 & $50 \cdot 0$ \\
\hline Retinol $(\mu \mathrm{g})$ & $602 \cdot 8$ & 76.9 & 554.9 & 88.4 & 0.5 & $610 \cdot 7$ & $92 \cdot 0$ & 0.9 & $9 \cdot 1$ & 45 & 41.5 \\
\hline$\beta$-Carotene $(\mu \mathrm{g})$ & $3881 \cdot 8$ & 242.5 & $4087 \cdot 2$ & 278.9 & 0.4 & 4219.9 & 291.8 & $0 \cdot 1$ & $3 \cdot 1$ & 27 & $32 \cdot 8$ \\
\hline Vitamin C (mg) & $115 \cdot 6$ & $7 \cdot 7$ & $132 \cdot 4$ & 8.9 & 0.03 & $156 \cdot 9$ & $10 \cdot 6$ & $<0.0001$ & $15 \cdot 6$ & 123 & $40 \cdot 4$ \\
\hline Vitamin $D(\mu \mathrm{g})$ & 3.1 & 0.2 & 3.4 & 0.3 & 0.2 & $15 \cdot 9$ & 3.0 & $<0.0001$ & $78 \cdot 6$ & 205 & $89 \cdot 4$ \\
\hline Vitamin $E(\mu \mathrm{g})$ & $12 \cdot 5$ & 0.4 & $12 \cdot 8$ & 0.4 & 0.4 & $19 \cdot 8$ & $4 \cdot 1$ & $<0.0001$ & 35.4 & 113 & $67 \cdot 6$ \\
\hline $\mathrm{Na}(\mathrm{mg})$ & 2903.5 & $65 \cdot 6$ & $2928 \cdot 1$ & $75 \cdot 4$ & 0.7 & 2929 & $75 \cdot 6$ & 0.7 & 0.0 & 54 & 0.6 \\
\hline $\mathrm{Ca}(\mathrm{mg})$ & $907 \cdot 8$ & 22.5 & 923.2 & $25 \cdot 8$ & 0.4 & $1112 \cdot 9$ & $152 \cdot 6$ & $<0.0001$ & $17 \cdot 0$ & 102 & $49 \cdot 3$ \\
\hline $\mathrm{Fe}(\mathrm{mg})$ & 13.4 & 0.3 & 14.9 & 0.4 & $<0.0001$ & $15 \cdot 9$ & 0.5 & $<0.0001$ & $6 \cdot 3$ & 84 & 20.4 \\
\hline $\mathrm{Mg}(\mathrm{mg})$ & $337 \cdot 3$ & 7.9 & 365.8 & 9.1 & 0.0002 & $389 \cdot 1$ & $10 \cdot 6$ & $<0.0001$ & $6 \cdot 0$ & 123 & $15 \cdot 1$ \\
\hline$P(\mathrm{mg})$ & $1320 \cdot 8$ & $27 \cdot 1$ & 1353.7 & 24.2 & $0 \cdot 1$ & 1354 & $24 \cdot 2$ & 0.1 & 0.0 & 33 & $2 \cdot 1$ \\
\hline $\mathrm{K}(\mathrm{mg})$ & 3229.9 & 59.5 & 3411.3 & 68.4 & 0.002 & $3416 \cdot 1$ & 68.5 & 0.001 & 0.1 & 33 & $2 \cdot 0$ \\
\hline $\mathrm{Zn}(\mathrm{mg})$ & 11.3 & 0.2 & $12 \cdot 0$ & 0.3 & 0.005 & $13 \cdot 0$ & 0.3 & $<0.0001$ & 7.7 & 117 & $26 \cdot 1$ \\
\hline
\end{tabular}

"In subjects with at least one $24 \mathrm{~h}$ dietary record after cancer diagnosis, normo-energy reporters. DS users were defined as subjects who used at least two DS after cancer diagnosis.

†Logistic regression analysis (performed to derive the $P$-value for the comparison between DS users and non-users) were adjusted for sex, age, number of $24 \mathrm{~h}$ dietary records and energy intake.

‡ Very small amounts of alcohol can be found in some DS or medicinal products as excipients (not as main active substance). 
Table 6. Dietary supplement (DS) use that may convey adverse effects in cancer survivors (NutriNet-Santé cohort study, France, 2014) (Number of subjects)

Use of $\beta$-carotene DS in smokers

$\beta$-carotene/current smokers

$\beta$-carotene/former smokers

Use of DS that should be avoided in

hormone-dependent cancer patients

Phyto-oestrogens/breast cancer

Chasteberry/breast cancer

Dehydroepiandrosterone/breast cancer

Phyto-oestrogens/ovarian or endometrial cancers

Phyto-oestrogens/prostate cancer

Saw palmetto/prostate cancer

Simultaneous use of DS and medications that may

lead to moderate-to-severe harmful interactions

Vitamin E/anticoagulant/antiplatelet agents

Niacin/statins

Safflower/anticoagulant/antiplatelet agents

Flaxseed/antiplatelet agents

Turmeric/anticoagulant/antiplatelet agents

$\mathrm{K} /$ spironolactone

Echinacea/antiplatelet agents

Ginseng/anticoagulant/antiplatelet agents

Ginkgo biloba/anticoagulant agents

Glucosamin/antiplatelet agents

$\mathrm{K} /$ captopril

Red yeast rice/anti-cholesterol drugs

Valerian/tamoxifen

Cinchona/anticoagulant agents

Milk thistle/anticoagulant agents

Soya/anticoagulant agents

but were closer to figures observed in other European countries $^{(23,24,28,40)}$. As suggested earlier ${ }^{(41,42)}$, cancer diagnosis may have influenced DS use. Indeed, the present findings showed that $28 \%$ of participants started, stopped or modified their DS use after cancer diagnosis. Further research into patients' beliefs regarding DS and cancer is needed to better understand these changes.

As observed in the NutriNet-Santé cohort for the general population $^{(43)}$, vitamins $\mathrm{B}_{6}$ and $\mathrm{C}$ and $\mathrm{Mg}$ DS were among the most frequently consumed DS. In addition, in the present population of cancer survivors, vitamin D emerged as the most frequent supplementation (used by $45 \%$ of DS users). This high prevalence of vitamin D DS use, especially in women, was consistent with prior investigations conducted in the United States ${ }^{(20,41,44)}$. Indeed, several anti-cancer treatments, such as aromatase inhibitors, which are used to treat postmenopausal breast cancers and androgen-deprivation therapy, which is used to treat prostate cancer ${ }^{(45)}$, may induce bone loss and thus justify vitamin D supplementation.

Cancer itself and its consequences appeared as a strong motivation for DS use. Another frequently cited motivation was to 'strengthen immune system', which is in line with previous studies ${ }^{(16,18)}$ and with the fact that the immune system is often altered by chemotherapy and radiotherapy treatments. To 'overcome tiredness' was also among the main motivations for DS use in the NutriNet-Santé general cohort ${ }^{(43)}$, and this was in line with the frequent use of vitamins $B_{6}$ and $C$ and $\mathrm{Mg}$ DS, which are recognised by the European Food Safety Authorities for their anti-fatigue properties ${ }^{(46-48)}$.
About $45 \%$ of DS use corresponded to self-medication, and $55 \%$ were taken following medical prescription or advice. This proportion varied across DS types. Whereas some types of self-medicated DS should be avoided by cancer survivors, others may truly be useful if consumed under medical supervision. For instance, this is the case for vitamin D, as discussed earlier. We consistently observed that the proportion of medical prescription or advice was higher for this nutrient (81\%).

A substantial proportion (35\%) of DS use was not discussed with a physician. Although this proportion was lower than that found in US studies $(56-68 \%)^{(16)}$, it remains a concern because of the potential interactions between DS and adjuvant therapy or other medications ${ }^{(9,13,14)}$. The main reason why patients did not inform their physician was simply that the latter did not ask about DS use by their patient, which is in line with the literature ${ }^{(49)}$. This suggests that physicians may not be fully aware of the medical importance of knowing whether their cancer patients are using DS. It has also been hypothesised that the perception of physician neutrality or indifference, or possibly even a fear of physician opposition, are reasons why patients may be hesitant to communicate with their physicians about DS use ${ }^{(16)}$. Another possibility is limited physician time during medical consultations.

Previous studies of DS use in cancer survivors in other countries also found that female $\operatorname{sex}^{(18,39,44)}$, higher education $^{(16,18,39,50)}$, non-smoking ${ }^{(17)}$ and lower BMI $^{(17,39)}$ were associated with DS use. These factors have also been associated with DS use in the general French population ${ }^{(43,51)}$. Although some studies have identified older age $\mathrm{ag}^{(39,44)}$ as a correlate of DS use, it was not a significant predictor in the present study's population. Likewise, a review on vitamin and mineral supplement use among US cancer survivors ${ }^{(16)}$ pointed out that DS use may differ by the type of cancer, but we did not find significant association in the present population between main cancer types after age and sex adjustment (data not shown).

As it has been observed in the general population ${ }^{(43)}$, DS use was associated with a healthier diet that already includes higher intakes of fibre and several vitamins and minerals from food only. The high contribution of DS to total nutrient intake highlights the importance of taking this source of intake into consideration both in clinical practice and in nutritional epidemiological studies. Few studies have provided detailed information about total micronutrient intake from food and supplements in cancer survivors ${ }^{(19,52)}$. Compared to DS users in the American Women's Healthy Eating and Living Study ${ }^{(19)}$, DS users in the present study had a lower total daily intake for almost all micronutrients, except for vitamin $\mathrm{D}$, folate, $\mathrm{Ca}$ and $\mathrm{Mg}$, which were similar in intake amount. These differences may notably be explained by the variability of DS formulations between the United States ${ }^{(53)}$ and Europe ${ }^{(54)}$.

Several interactions between herbal or vitamin/mineral DS and drugs that may lead to moderate-to-major adverse effects have been well documented ${ }^{(9,13-15)}$. As recommended by official authorities, some DS should also be avoided by certain cancer patients, such as phyto-oestrogens in oestrogen receptor-positive cancers ${ }^{(6,9,14)}$. Another potentially harmful 
practice is the use of $\beta$-carotene DS, which is recognised for its association with increased lung and gastric cancers risk ${ }^{(5,10,55)}$ in current smokers but also maybe in former smokers ${ }^{(11)}$. A relatively high proportion of DS users in the present study (18\%) were concerned by such potentially harmful practices. Potentially problematic drug-nutrient interactions reported in the present study mainly concerned anticoagulants/antiplatelet agents and not specifically anti-cancer treatments, which may be explained by the fact that the DS questionnaire was administered 22 months after diagnosis on average.

The strengths of the present study are that it included a large number of cancer cases, detailed data about DS use (including precise doses and composition) and its dietary and lifestyle correlates, information about drugs taken simultaneously, and it was original in a French/European context.

The main limitation was that the present study's population may not be representative of all French male and female cancer survivors, given that the NutriNet-Santé study involved volunteers who accepted to participate in a cohort on nutrition and health. Compared to national estimates ${ }^{(56,57)}$, the NutriNet-Santé study included more women than men and more individuals who belong to higher socio-professional categories. In addition, some eligible cancer survivors did not answer the DS questionnaire. Compared to respondents, non-respondents were more likely to be women, to have more children and to have cancers other than those mainly represented in the cohort $(P<0 \cdot 0001$, data not shown). However, response rates to the DS questionnaire was high (73\%) compared to similar epidemiological studies ${ }^{(18,21,42,50,58)}$. In addition, because the DS questionnaire was administered 22 months after diagnosis on average, a recall bias may have occurred for DS that were not currently being taken by the participants. Finally, although the sample size was reasonably large overall, only the main cancer types (i.e. breast and prostate) could be analysed, and other types with lower incidence could not be investigated separately.

In conclusion, the present study provides new and detailed information about DS use and its correlates in a large sample of French cancer survivors. The findings suggest that DS use was widespread in the present population and substantially contributed to total nutrient intake, with $14 \%$ of subjects initiating DS use after diagnosis. DS users had an overall healthier profile (in terms of diet, smoking status and BMI) than non-users. The present study highlighted the absence of communication about DS use between patients and healthcare professionals (for $35 \%$ of reported DS) and the importance of self-medication ( $45 \%$ ). Worryingly, a substantial proportion of potentially harmful practices were detected (in 18\% of DS users), including the simultaneous use of vitamin $\mathrm{E}$ and anticoagulant/antiplatelet agents, the use of $\beta$-carotene by smokers and the use of phyto-oestrogens by hormone-dependent cancer patients. Physicians should be encouraged to more routinely discuss DS use with their cancer patients and to warn them about potential adverse effects. Finally, given the widespread use of DS in cancer patients and survivors, further etiological research is needed to better elucidate its impact on cancer prognosis, the risk of recurrence and the risk of second cancer.

\section{Acknowledgements}

The authors thank Younes Essedic, Paul Flanzy, Mohand Ait Oufella, Yasmina Chelghoum and Than Duong Van (computer scientists), Florence Charpentier (dietitian), Elise Martin (communication assistant), Nathalie Arnault, Véronique Gourlet, Fabien Szabo, Laurent Bourhis and Stephen Besseau (statisticians) and Rachida Mehroug (logistics assistant) for their technical contributions to the NutriNet-Santé study.

The present work was supported by the 2013 Research Prize from the French Nutrition Society and the French National Institute of Cancer (no. DEPREV14-027). Camille Pouchieu was funded by a grant from the French Ministry of Research and Higher Education (no. 11/ED G/UREN/2011). Philippine Fassier was funded by a grant from the Cancéropôle Ile-de-France (public funding from the Paris region). The NutriNet-Santé study was supported by the following institutions: Ministère de la Sante; Institut de Veille Sanitaire; Institut National de la Prévention et de l'Education pour la Santé; Fondation pour la Recherche Médicale; Institut de Recherche en Santé Publique; Institut National de la Santé et de la Recherche Médicale; Institut National de la Recherche Agronomique; Conservatoire National des Arts et Métiers; and Université Paris 13.

The author's responsibilities were as follows: C. P. and M. T. designed the research; S. H. and M. T. conducted the research; C. P. performed statistical analysis; C. P. and M. T. wrote the paper; P. F., N. D.-P., L. Z., P. B., M. T., I. B., S. H., P. G., P. C. and P. L.-M. contributed to the data interpretation and revised each draft for important intellectual content; and M. T. had primary responsibility for final content. All authors have read and approved the final manuscript.

None of the authors has any conflict of interest to declare.

\section{References}

1. Giovannucci E \& Chan AT (2010) Role of vitamin and mineral supplementation and aspirin use in cancer survivors. $J$ Clin Oncol 28, 4081-4085.

2. Block KI, Koch AC, Mead MN, et al. (2008) Impact of antioxidant supplementation on chemotherapeutic toxicity: a systematic review of the evidence from randomized controlled trials. Int J Cancer 123, 1227-1239.

3. Tang JY, Fu T, LeBlanc E, et al. (2011) Calcium plus vitamin D supplementation and the risk of nonmelanoma and melanoma skin cancer: post hoc analyses of the women's health initiative randomized controlled trial. J Clin Oncol 29, 3078-3084.

4. Bougnoux P, Hajjaji N, Ferrasson MN, et al. (2009) Improving outcome of chemotherapy of metastatic breast cancer by docosahexaenoic acid: a phase II trial. Br J Cancer 101, 1978-1985.

5. Latino-Martel P, Bachmann P \& et le groupe de travail SFNEP oncology nutrition guidelines (2012) Antioxydative nutritional supplements throughout the cancer treatment process. Nutr Clin Metab 26, 238-246.

6. AFSSA Groupe de Travail phyto-oestrogènes (2005) Sécurité et bénéfices des phyto-estrogènes apportés par l'alimentation Recommandations (Safety and Benefits of Phytoestrogens from Food - Recommendations). Maison-Alfort: AFSSA. 
7. Bairati I, Meyer F, Gélinas M, et al. (2005) A randomized trial of antioxidant vitamins to prevent second primary cancers in head and neck cancer patients. I Natl Cancer Inst 97, 481-488.

8. Greenlee H, Kwan ML, Kushi LH, et al. (2012) Antioxidant supplement use after breast cancer diagnosis and mortality in the Life After Cancer Epidemiology (LACE) cohort. Cancer 118, 2048-2058.

9. Tsai HH, Lin HW, Simon Pickard A, et al. (2012) Evaluation of documented drug interactions and contraindications associated with herbs and dietary supplements: a systematic literature review. Int J Clin Pract 66, 1056-1078.

10. Druesne-Pecollo N, Latino-Martel P, Norat T, et al. (2010) $\beta$-Carotene supplementation and cancer risk: a systematic review and metaanalysis of randomized controlled trials. Int J Cancer 127, 172-184.

11. Touvier M, Kesse E, Clavel-Chapelon F, et al. (2005) Dual association of $\beta$-carotene with risk of tobacco-related cancers in a cohort of French women. J Natl Cancer Inst 97, 1338-1344.

12. Meyer F, Bairati I, Fortin A, et al. (2008) Interaction between antioxidant vitamin supplementation and cigarette smoking during radiation therapy in relation to long-term effects on recurrence and mortality: a randomized trial among head and neck cancer patients. Int J Cancer 122, 1679-1683.

13. Tsai HH, Lin H-W, Lu Y-H, et al. (2013) A review of potential harmful interactions between anticoagulant/antiplatelet agents and Chinese herbal medicines. PLOS ONE 8, e64255.

14. Cassileth BR \& Lucarelli C (2003) Herb-Drug Interactions in Oncology. Hamilton, ON: B.C. Decker.

15. Sparreboom A, Cox MC, Acharya MR, et al. (2004) Herbal remedies in the United States: potential adverse interactions with anticancer agents. J Clin Oncol 22, 2489-2503.

16. Velicer CM \& Ulrich CM (2008) Vitamin and mineral supplement use among US adults after cancer diagnosis: a systematic review. J Clin Oncol 26, 665-673.

17. Bright-Gbebry M, Makambi K, Rohan J, et al. (2011) Use of multivitamins, folic acid and herbal supplements among breast cancer survivors: the black women's health study. BMC Complement Altern Med 11, 30.

18. Ferrucci LM, McCorkle R, Smith T, et al. (2009) Factors related to the use of dietary supplements by cancer survivors. J Altern Complement Med 15, 673-680.

19. Saquib J, Rock CL, Natarajan L, et al. (2011) Dietary intake, supplement use, and survival among women diagnosed with early-stage breast cancer. Nutr Cancer 63, 327-333.

20. Zirpoli G, Brennan P, Hong CC, et al. (2013) Supplement use during an intergroup clinical trial for breast cancer (S0221). Breast Cancer Res Treat 137, 903-913.

21. Greenlee H, Kwan M, Ergas I, et al. (2014) Changes in vitamin and mineral supplement use after breast cancer diagnosis in the Pathways Study: a prospective cohort study. BMC Cancer 14, 382.

22. Fox P, Butler M, Coughlan B, et al. (2012) Using a mixed methods research design to investigate complementary alternative medicine (CAM) use among women with breast cancer in Ireland. Eur J Oncol Nurs 17, 490-497.

23. Molassiotis A, Panteli V, Patiraki E, et al. (2006) Complementary and alternative medicine use in lung cancer patients in eight European countries. Complement Ther Clin Pract 12, 34-39.

24. Westerlund A, Steineck G, Bälter K, et al. (2011) Dietary supplement use patterns in men with prostate cancer: the Cancer Prostate Sweden study. Ann Oncol 22, 967-972.
25. Ritchie MR (2007) Use of herbal supplements and nutritional supplements in the UK: what do we know about their pattern of usage? Proc Nutr Soc 66, 479-482.

26. Hutchinson J, Burley VJ, Greenwood DC, et al. (2011) High-dose vitamin C supplement use is associated with self-reported histories of breast cancer and other illnesses in the UK Women's Cohort Study. Public Health Nutr 14, 768-777.

27. Pedersen CG, Christensen S, Jensen AB, et al. (2009) Prevalence, socio-demographic and clinical predictors of post-diagnostic utilisation of different types of complementary and alternative medicine (CAM) in a nationwide cohort of Danish women treated for primary breast cancer. Eur J Cancer 45, 3172-3181.

28. Molassiotis A, Fernandez-Ortega P \& Pud D (2005) Complementary and alternative medicine use in colorectal cancer patients in seven European countries. Complement Ther Med 13, 251-257.

29. Hercberg S, Castetbon K, Czernichow S, et al. (2010) The Nutrinet-Santé Study: a web-based prospective study on the relationship between nutrition and health and determinants of dietary patterns and nutritional status. BMC Public Health 10, 242

30. Touvier M, Kesse-Guyot E, Mejean C, et al. (2011) Comparison between an interactive web-based self-administered $24 \mathrm{~h}$ dietary record and an interview by a dietitian for large-scale epidemiological studies. Br J Nutr 105, 1055-1064.

31. Vergnaud AC, Touvier M, Méjean C, et al. (2011) Agreement between web-based and paper versions of a socio-demographic questionnaire in the NutriNet-Santé study. Int $J$ Public Health 56, 407-417.

32. Touvier M, Mejean C, Kesse-Guyot E, et al. (2010) Comparison between web-based and paper versions of a self-administered anthropometric questionnaire. Eur J Epidemiol 25, 287-296.

33. WHO (1993) ICD-1O, International Classification of Diseases and Related Health Problems.10th revision. Geneva, Switzerland: WHO.

34. VIDAL (2014) Medication database for the French market VIDAL. http://www.evidal.fr (accessed April 2014).

35. Craig CL, Marshall AL, Sjöström M, et al. (2003) International physical activity questionnaire: 12-country reliability and validity. Med Sci Sports Exerc 35, 1381-1395.

36. Hercberg S, Deheeger M \& Preziosi P (2002) SU.VI.MAX. Portions alimentaires manuel-photos pour l'estimation des quantités (SU.VI.MAX. Photograph Book for the Estimation of Portion Sizes). Paris: Editions polytechnica.

37. Hercberg S (2013) Table de composition des aliments NutriNet-Santé (Food Composition Table - NutriNet-Santé). Paris: Editions Économica.

38. Black AE (2000) Critical evaluation of energy intake using the Goldberg cut-off for energy intake:basal metabolic rate. A practical guide to its calculation, use and limitations. Int J Obes Relat Metab Disord 24, 1119-1130.

39. Miller PE, Vasey JJ, Short PF, et al. (2009) Dietary supplement use in adult cancer survivors. Oncol Nurs Forum 36, 61-68.

40. Velentzis L, Keshtgar M, Woodside J, et al. (2011) Significant changes in dietary intake and supplement use after breast cancer diagnosis in a UK multicentre study. Breast Cancer Res Treat 128, 473-482.

41. Patterson RE, Neuhouser ML, Hedderson MM, et al. (2003) Changes in diet, physical activity, and supplement use among adults diagnosed with cancer. J Am Diet Assoc 103, $323-328$.

42. Wiygul JB, Evans BR, Peterson BL, et al. (2005) Supplement use among men with prostate cancer. Urology 66, 161-166. 
43. Pouchieu C, Andreeva V, Péneau S, et al. (2013) Sociodemographic, lifestyle and dietary correlates of dietary supplement use in a large sample of French adults: results from the NutriNet-Santé cohort study. Br J Nutr 110, 1480-1491.

44. Osian SR, Leal AD, Allmer C, et al. (2014) Widespread use of complementary and alternative medicine (CAM) among nonHodgkin lymphoma (NHL) survivors. Leuk Lymphoma $\mathbf{5 6}$, 434-439.

45. Limburg C, Maxwell C \& Mautner B (2014) Prevention and treatment of bone loss in patients with nonmetastatic breast or prostate cancer who receive hormonal ablation therapy. Clin J Oncol Nurs 18, 223-230.

46. EFSA Panel on Dietetic Products NaAN (2010) Scientific opinion on the substantiation of health claims related to magnesium and hormonal health (ID 243), reduction of tiredness and fatigue (ID 244), contribution to normal psychological functions (ID 245, 246), maintenance of normal blood glucose concentrations (ID 342), maintenance of normal blood pressure (ID 344, 379 ), protection of DNA, proteins and lipids from oxidative damage (ID 351), maintenance of the normal function of the immune system (ID 352), maintenance of normal blood pressure during pregnancy (ID 367), resistance to mental stress (ID 375,381 ), reduction of gastric acid levels (ID 376), maintenance of normal fat metabolism (ID 378) and maintenance of normal muscle contraction (ID 380, ID 3083) pursuant to Article 13(1) of Regulation (EC) No 1924/2006. EFSA J 8, 1-35.

47. EFSA Panel on Dietetic Products NaAN (2010) Scientific opinion on the substantiation of health claims related to vitamin $\mathrm{B} 6$ and contribution to normal homocysteine metabolism (ID 73, 199), maintenance of normal bone (ID 74), maintenance of normal teeth (ID 74), maintenance of normal hair (ID 74), maintenance of normal skin (ID 74), maintenance of normal nails (ID 74), contribution to normal energy-yielding metabolism (ID 75, 214), contribution to normal psychological functions (ID 77), reduction of tiredness and fatigue (ID 78), and contribution to normal cysteine synthesis (ID 4283) pursuant to Article 13(1) of Regulation (EC) No 1924/2006. EFSA J 8, 1-35.

48. EFSA Panel on Dietetic Products NaAN (2010) Scientific opinion on the substantiation of health claims related to vitamin $C$ and reduction of tiredness and fatigue (ID 139, 2622), contribution to normal psychological functions (ID 140), regeneration of the reduced form of vitamin E (ID 202), contribution to normal energy-yielding metabolism (ID 2334, 3196), maintenance of the normal function of the immune system (ID 4321) and protection of DNA, proteins and lipids from oxidative damage (ID 3331) pursuant to Article 13(1) of Regulation (EC) No 1924/2006. EFSA J 8, 1-20.
49. Hall JD, Bissonette EA, Boyd JC, et al. (2003) Motivations and influences on the use of complementary medicine in patients with localized prostate cancer treated with curative intent: results of a pilot study. BJU Int 91, 603-607.

50. Walshe R, James EL, Macdonald-Wicks L, et al. (2012) Socio-demographic and medical correlates of the use of biologically based complementary and alternative medicines amongst recent Australian cancer survivors. Prev Med 54, $23-26$.

51. Touvier M, Kesse E, Volatier JL, et al. (2006) Dietary and cancer-related behaviors of vitamin/mineral dietary supplement users in a large cohort of French women. Eur J Nutr 45, 205-214.

52. Inoue-Choi M, Greenlee H, Oppeneer SJ, et al. (2014) The association between postdiagnosis dietary supplement use and total mortality differs by diet quality among older female cancer survivors. Cancer Epidemiol Biomarkers Prev 23, 865-875.

53. National Institutes of Health (NIH) Office of Dietary Supplements (ODS) and National Library of Medicine (NLM) (2014) Dietary Supplement Label Database. http://www.dsld.nlm.nih.gov/dsld/index.jsp (accessed April 2014).

54. Lentjes MA, Bhaniani A, Mulligan AA, et al. (2011) Developing a database of vitamin and mineral supplements (ViMiS) for the Norfolk arm of the European Prospective Investigation into Cancer (EPIC-Norfolk). Public Health Nutr 14, 459-471.

55. AICR/WCRF (2007) American Institute for Cancer Research/ World Cancer Research Fund - Food, Nutrition, Physical Activity and the Prevention of Cancer: a Global Perspective. Washington, DC: AICR.

56. INSEE (Institut National de la Statistique et des Etudes Economiques) (2014) Population by sex and age on 1st January 2014, France except Mayotte. http://www.insee.fr/en/ themes/detail.asp?reg_id=0\&ref_id=bilan-demo\&page $=$ don nees-detaillees/bilan-demo/pop_age2b.htm (accessed April 2014).

57. INSEE (Institut National de la Statistique et des Etudes Economiques) (2013) Population en emploi selon le sexe et la catégorie socioprofessionnelle en 2012 (Employed population by sex and occupation in 2012). http://www. insee.fr/fr/themes/tableau.asp?reg_id=0\&ref_id=NATnon 03173 (accessed April 2014).

58. Greenlee H, Gammon MD, Abrahamson PE, et al. (2009) Prevalence and predictors of antioxidant supplement use during breast cancer treatment: the Long Island Breast Cancer Study Project. Cancer 115, 3271-3282. 